\title{
CONHECIMENTO ECOLÓGICO LOCAL DE PRODUTORES RURAIS SOBRE BIODIVERSIDADE E IMPACTOS AMBIENTAIS NAS VEGETAÇÕES RIPÁRIAS EM DIORAMA, ESTADO DE GOIÁS
}

\author{
LOCAL ECOLOGICAL KNOWLEDGE OF RURAL PRODUCERS ON BIODIVERSITY AND ITS \\ ENVIRONMENTAL IMPACTS IN RIPARIAN VEGETATIONS AT DIORAMA, STATE OF GOIÁS, \\ BRAZIL
}

${ }^{1}$ Denise Aparecida CARVALHO; ${ }^{2}$ Karine Alves da Silva XAVIER; ${ }^{3}$ Mateus França de SOUZA; ${ }^{4}$ Daniel BLAMIRES*

${ }^{1}$ Programa de Pós-Graduação em Recursos Naturais do Cerrado (PPGAS). Universidade Estadual de Goiás (UEG), Campus de Ciências Exatas e Tecnológicas, Anápolis, GO, Brasil. ${ }^{2}$ Rua Vereador Antônio Machado. Qd. 13, LT. 465, Centro, CEP 76260-000, Diorama Goiás, Brasil. ${ }^{3}$ Perícia Oficial e Identificação Técnica do Estado do Mato Grosso (POLITEC). Gerência Regional da POLITEC de Água Boa - MT, Água Boa, MT, Brasil. ${ }^{4}$ Universidade Estadual de Goiás, Campus Iporá, GO, Brasil.*daniel.blamires@ ueg.br

\section{RESUMO}

Submitted: 06/05/2019; Accepted: 04/06/2019

Este estudo avaliou a percepção de 30 agricultores familiares a respeito da vegetação ripária no município de Diorama, mesorregião noroeste de Goiás, através do conhecimento local de vegetais e animais, uso dos recursos naturais, além dos impactos ambientais nestas fisionomias e na paisagem. Foram realizadas entrevistas semiestruturadas com os participantes, e as informações obtidas analisadas qualitativa e quantitativamente. Sessenta e uma etnoespécies vegetais foram relatadas $(\mathrm{S}=61)$, sendo a maioria utilizada para fins medicinais $(54 \%)$ e extração de madeira (33\%). Foram relatadas 69 etnoespécies animais, sendo a caça uma atividade pouco citada, porém significativa entre os entrevistados (16\%). A pesca, praticada por 33\% dos entrevistados, serve apenas para recreação e subsistência, tendo sido abandonada por muitos com a redução da água e dos peixes nos mananciais. Todos os entrevistados declararam conservar a vegetação ripária para garantir os serviços ecossistêmicos. A substituição da paisagem nativa do município por atividades agropecuárias foi associada por todos os entrevistados ao aumento da temperatura, redução das chuvas e da água nos mananciais. Este estudo demonstrou que os entrevistados possuem ampla percepção com relação às vegetações ripárias, e demonstram conhecimento sobre a importância da preservação para evitar prejuízos ambientais e econômicos. Entretanto, considerando a extração de madeira e a caça relatada por grande parte dos entrevistados, atividades de conscientização ambiental deveriam ser desenvolvidas nas comunidades estudadas. São necessários mais estudos sobre percepção das vegetações ripárias por produtores rurais, considerando a importância ecológica e econômica destas fisionomias, tanto no estado de Goiás quanto em todo o Cerrado.

PALAVRAS-CHAVE: Brasil Central; Noroeste goiano; Etnobiologia; Conhecimento empírico; serviços ecossistêmicos

\begin{abstract}
This study evaluated the perception of 30 families of farmers concerning riparian vegetation in the municipality of Diorama, northwestern mesoregion of Goiás, Brazil, through local knowledge of plants and animals, use of natural resources, as well as environmental impacts in these physiognomies and landscape. The participants took part in a semi-structured interview, and the information obtained was analyzed qualitatively and quantitatively. Sixty-one plant ethnoespecies were reported $(\mathrm{S}=61)$, most of them being used for medicinal purposes $(54 \%)$ and timber extraction $(33 \%)$. A total of 69 animal ethnoespecies was reported. Hunting was a scarce but significant activity according to the interviewees (16\%). Fishing, practiced by $33 \%$ of the interviewees, is a practice of recreation and subsistence, which has been abandoned by many due to the reduction of water and fish in the springs. All interviewees stated that they conserved riparian vegetation to guarantee ecosystem services. The replacement of the municipality native landscape by agricultural implementation was associated among all the interviewees to the increase in temperature, the reduction of rainfall and water in the springs. This study confirmed that the interviewees have a wide perception regarding riparian vegetation, demonstrating knowledge about the importance of preservation in order to avoid both environment and economic damages. Nonetheless, considering the extraction of timber and hunting, mentioned by most of the interviewees, environmental awareness activities should be developed in the communities where this study was done. Further studies on the perception of riparian vegetation by rural producers are necessary, considering the ecological and economic importance of these physiognomies in both, the state of Goiás and whole Cerrado.
\end{abstract}

KEYWORDS: Central Brazil; Northeastern of Goiás State; Ethnobiology; Empirical knowledge; Ecosystem services. 


\section{INTRODUÇÃO}

A expansão humana no ambiente promove a fragmentação e eliminação de formações florestais nativas, bem como a diminuição dos recursos naturais (FAHRIG, 2003). Neste contexto, a ciência atual requer mais ferramentas para lidar eficazmente com as questões ambientais (STEVENSON, 2005). Assim, a etnobiologia, ou o estudo do conhecimento biológico de determinados grupos étnicos sobre plantas, animais e suas inter-relações (ANDERSON et al., 2011), é uma importante alternativa para o estabelecimento de políticas conservacionistas. Importante ressaltar que a etnobiologia é mais intimamente associada a estudos que enfoquem a classificação local de sistemas para espécies biológicas (ANDERSON, 2011; PRADO e MURIETA, 2015), sendo a etnoecologia associada aos modos locais de entendimento das relações entre humanos e seu ambiente natural, incluindo aspectos ecológicos como solo, clima, comunidades ecológicas e outros fatores ambientais (HUNN, 2007; PRADO e MURIETA, 2015).

Somente nas últimas décadas o conhecimento adquirido pela relação homem e ambiente natural tem recebido a devida atenção para interpretação e solução de problemas ambientais, bem como valorização das diversas culturas humanas (LOPES et al., 2010). Além da perda de informações relevantes sobre recursos naturais, que acompanha a ocupação de ambientes silvestres (ROCHAMENDES et al., 2005), o desenvolvimento tecnológico altera padrões culturais das sociedades humanas, resultando na perda de valores inerentes à relação entre homem e meio ambiente (DIAMOND, 1966). Assim, o conhecimento ecológico local (local enviromental knowledge - LEK) permite tanto acessar informações ainda não obtidas cientificamente, quanto entender aspectos culturais diversos associados ao convívio humano com o meio circundante (BART, 2006). Tais informações propiciam um resgate cultural das diversas sociedades humanas, e maior conhecimento acerca dos recursos naturais (FARIAS e ALVES, 2007).

Análises qualitativas e quantitativas, nas quais métodos descritivos associam-se a métodos numéricos de coleta e análise de dados, são comuns em pesquisa etnobiológica (EMPERAIRE e PERONI, 2007). A qualidade dos dados coletados e da pesquisa ocorre pelo rigor científico empregado, independente da escolha do método (LOPES et al., 2010), havendo muitos fatores a serem considerados em estudos com humanos, como idade, tempo de moradia no local, entre outros, que nem sempre favorecem cálculos exatos (DAVIS e WAGNER, 2003). Neste contexto, um importante método é o uso de entrevistas semi-estruturadas, que combinam perguntas abertas e fechadas, proporcionando ao informante discorrer sobre o tema de forma similar a uma conversa informal, e tem como principal vantagem uma melhor amostra da população de interesse (BONI e QUARESMA, 2005).

No Brasil, denonimam-se Áreas de Preservação Permantente (APPs) as áreas cobertas ou não por vegetação nativa, importantes para preservar os recursos hídricos, a paisagem, a estabilidade geológica, a biodiversidade, o solo, e assegurar o bem-estar das populações humanas (OLIVEIRA e WOLSKI, 2012). As faixas marginais a quaisquer mananciais, neste contexto, são consideradas APPs (OLIVEIRA e WOLSKI, 2012), inclusive as vegetações ripárias, que são quaisquer fisionomias que margeiem corpos hídricos (HINKEL, 2003). No Cerrado, as vegetações ripárias são indispensáveis para proteção e conservação dos recursos hídricos, pois evitam o assoreamento, protegem o solo da erosão, o rio da contaminação de produtos químicos, e mantém a temperatura do ecossistema aquático constante (DURIGAN e SILVEIRA, 1999).

Nos últimos anos, importantes estudos sobre o conhecimento empírico de plantas, animais e o ambiente foram desenvolvidos em Goiás, no centro do Cerrado, abrangendo tanto comunidades nãotradicionais (CUNHA et al., 2007; GRANDE et al., 2016; SÁ et al., 2017), quanto tradicionais (BARBOSA et al., 2017; SOUZA et al., 2017). Entretanto, nenhum trabalho similar foi elaborado no município de Diorama. Assim, este estudo analisou a percepção de pequenos produtores rurais deste município sobre vegetações ripárias, abrangendo o conhecimento empírico de plantas e animais, o uso dos recursos naturais, e os impactos nestas fisionomias e na paisagem.

\section{MATERIAL E MÉTODOS \\ Área de estudo}

Este trabalho foi realizado no município de Diorama, mesorregião noroeste do estado de

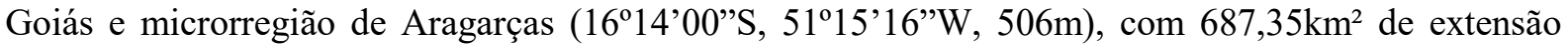
territorial (IMB, 2016), e distante aproximadamente $245 \mathrm{~km}$ da capital Goiânia (Figura 1). Diorama tem um clima tropical, com mais pluviosidade no verão que no inverno, classificado como $A w$ 
segundo Köppen e Geiger (CLIMATE-DATA, 2017). A vegetação predominante no município eram as formações savânicas típicas de Cerrado, intercaladas secundariamente por florestas semidecíduas e formações campestres (SILVA et al., 2006). A paisagem de Diorama foi alterada nas últimas décadas, já que atualmente sua economia baseia-se na pecuária extensiva de corte e leite, além de lavouras temporárias de soja Glycine max (L.) Merr., cana-de-açúcar Saccharum spp., milho Zea mays L. e mandioca Manihot esculenta Crantz (IMB, 2014).

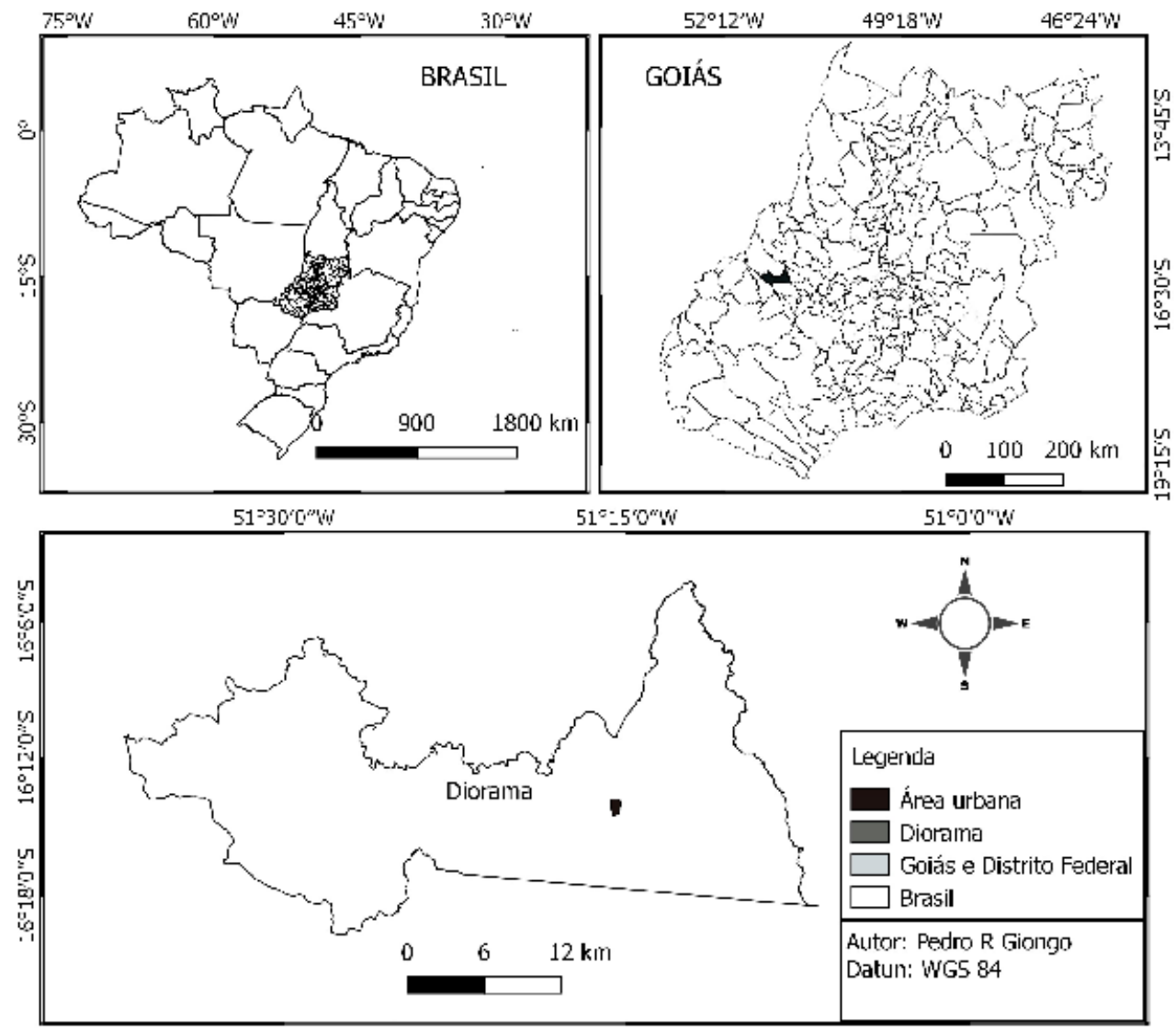

Figura 1: Localização geográfica do município de Diorama, estado de Goiás, Brasil.

A população total de Diorama, que diminuiu entre 2000 a 2009, é de 2479 habitantes, com 1506 residentes na área urbana e 973 na área rural (IBGE, 2010). A taxa de analfabetismo é de 11,7\% (DATASUS, 2016), e o Índice de Desenvolvimento Humano (IDH) de 0,729 (ATLAS, 2013).

\section{Coleta dos dados}

A pesquisa foi realizada na zona rural do município em abril, maio, junho e outubro de 2016 , com 30 pequenos produtores rurais (1 entrevistado/propriedade), pertencentes a oito comunidades: Lajeado (7), Rio dos Bois (7), Alcantilado (7), Córrego das Vacas (4), Córrego D'antas (2), Catingueiro (1), Palmito (1) e Olho D’água (1). Os entrevistados foram selecionados conforme os seguintes parâmetros: i) residência fixa na zona rural; ii) ausência de instrução técnica formal (cursos técnicos, curso superior ou especialização em ciências ambientais/biológicas); iii) idade mínima de 18 anos; iv) disponibilidade para ser entrevistado. As entrevistas ocorreram nas residências, com duração média de 30min, iniciando-se após a explicação dos objetivos do trabalho e a obtenção do consentimento do entrevistado em participar da pesquisa. Foram solicitados aos entrevistados que concordaram em participar a assinatura, em duas vias, do "Termo de Consentimento e Livre Esclarecido", autorizado conforme o Comitê de Ética e Pesquisa do Instituto de Ciências Farmacêuticas de Estudos e Pesquisas S/S, parecer ético número 1209815 (CAAE: 46959815.3.0000.5572), ficando uma cópia destinada aos pesquisadores e outra ao entrevistado. Cada entrevista foi gravada integralmente com gravador de voz SONY ICD-PX312, com armazenamento em 
formato digital ( Ciências Exatas e Tecnológicas Henrique Santillo (CCET), da Universidade Estadual de Goiás (UEG), em Anápolis.

As entrevistas foram realizadas com o método do questionário semi-estruturado, que combina perguntas fechadas e abertas, proporcionando o entrevistado a discorrer sobre o tema (BONI e QUARESMA, 2005). Este método capta grande quantidade de informações, revelando tanto aspectos esperados como não previstos (HUNTINGTON, 1998). Assim, as entrevistas seguiram três etapas básicas, sendo inicialmente listados dados socioeconômicos dos entrevistados como sexo, idade, ocupação, nível de instrução e rendimento médio mensal. A segunda etapa das entrevistas consistiu no relato etnobiológico de vegetais (listagem das etnoespécies, uso de plantas para fins medicinais e extração de madeira) e animais (listagem das etnoespécies, atividades de caça e pesca). A última etapa abrangeu uma perspectiva etnoecológica sobre a percepção conservacionista da vegetação ripária e do ambiente ao redor.

\section{Análise dos dados}

O conceito de etnoespécie empregado neste estudo foi utilizado como sinônimo de nome popular (MEDEIROS et al., 2016), e os nomes vernaculares obtidos foram transcritos da mesma forma como citados pelos entrevistados (SOUZA et al., 2017). O conteúdo das respostas foi analisado mediante tabulação dos dados, com estatísticas descritivas (média, desvio padrão e porcentagem), sob uma perspectiva qualitativa e quantitativa. As análises qualitativas foram efetuadas com a interpretação do discurso dos entrevistados buscando, sempre que possível, justapor o modelo percebido ao conhecimento científico (BARBOSA et al., 2017).

\section{RESULTADOS}

\section{Perfil socioeconômico dos entrevistados}

Dos trinta entrevistados na área rural de Diorama, dezesseis (16 ou 53\%) são do sexo masculino, e 14 (47\%) do sexo feminino. Os homens apresentaram idades entre 31 e 84 anos (Média $=57,5 \pm 37,5$ ). A idade das mulheres variou de 41 a 71 anos (Média=56,0 021,2 ). Com relação à ocupação principal, os entrevistados se declararam trabalhadores rurais, aposentados, funcionários públicos, serviços-do-lar, faxineira e técnica em enfermagem, sendo mais representativa a primeira atividade, com cerca de 57\% dos entrevistados, seguido de serviços-do-lar (20\%) e aposentados (13\%). As demais atividades representaram apenas $10 \%$ dos entrevistados. Entretanto, todos os entrevistados efetuam atividades do campo como tratar e ordenhar o gado, ou alimentar outros animais domésticos.

Com relação ao nível de instrução, a maioria (57\%) declarou ensino fundamental incompleto, $23,5 \%$ ensino médio completo, e 13,5\% ensino fundamental completo. As categorias ensino superior completo e ensino superior incompleto tiveram ambas apenas 1 entrevistado $(3,0 \%$ cada, respectivamente). O rendimento médio mensal predominante das famílias $(57 \%)$ abrange até três salários mínimos. Sete entrevistados (23\%) declararam receber mais de cinco salários mínimos, e $20 \%$ declararam receber de 3 a 5 salários mínimos.

\section{Conhecimento e utilização da vegetação ripária}

Foram relatados o uso de 61 etnoespécies vegetais, sendo as mais frequentes: gameleira Ficus sp. (12), sangra D’água Croton urucurana Baill. (11), e o jatobá Hymenaea courbaril L. 1753 (09). Das 61 espécies vegetais citadas, $33(54 \%)$ são utilizadas para fins medicinais, como a sangra d'água C. urucurana (8) para infecção, o jatobá $H$. courbaril (3) para tosse e câncer de próstata, e o esporão Celtis iguanea (Jacq.) Sarg. (3) para problema renal. Sobre a extração da madeira na vegetação ripária, 10 entrevistados (33\%) declararam retirar madeira para "uso próprio", sendo sucupira Pterodon emarginatus Vogel (3), angico Anadenanthera falcata (Benth.) Speg. (2), ipê Handroantus spp. (2), jatobá $H$. courbaril (2) e aroeira Myracrodruon urundeuva (Allemão) Engl. (2) as espécies mais citadas. Um dos entrevistados não especificou o tipo de madeira que retirava. Aproximadamente 10 entrevistados (33\%) retiram plantas para fins ornamentais, como samambaias Pteridophyta (5), orquídeas Orchidaceae (4) e bambus Poaceae (1); todos para "uso próprio". Não ficou evidente se o bambu retirado é da espécie exótica Bambusa sp., ou nativa como a taboca Guadua sp.

Cerca de 69 etnoespécies animais foram relatadas, sendo macaco-prego Sapajus libidinosus (Spix, 1823) (22), quati Nasua nasua Linnaeus, 1766 (21), e mutum Crax fasciolata Spix, 1825 (18) 
as mais frequentes. Quanto ao uso da vegetação ripária para caça e pesca, 25 (83\%) dos entrevistados disseram não caçar animais. As espécies citadas entre os que confirmaram caçar (17\%) foram: capivara Hydrochoerus hydrochaeris Linnaeus, 1766, veado-catingueiro Mazama gouazoubira Fisher, 1814, paca Cuniculus paca (Linnaeus, 1766), tatu Dasypopidae, tamanduá-bandeira Myrmecophaga tridactyla Linnaeus, 1758, anta Tapirus terrestris Linnaeus, 1758 e saracura Aramides sp. Todos alegaram a caça para consumo próprio.

A pesca recreativa e de subsistência é praticada por 10 (33\%) dos entrevistados, sendo o lambari Astyanax sp., traira Hoplias sp. e piau Leporinus sp. as espécies mais pescadas. Seis entrevistados $(20 \%)$ alegaram pescar no passado para consumo próprio e lazer, mas abandonaram a atividade devido à redução da água e do pescado nos mananciais, conforme um dos relatos:

"Assoreou o rio e acabou o peixe" E10

Oito entrevistados (26\%) utilizam a área da vegetação ripária para lazer, mas nenhum declarou lucrar com turismo em suas propriedades

\section{Percepção sobre a conservação da vegetação ripária e do meio ambiente.}

Todos os entrevistados admitem saber sobre a existência de leis de proteção da vegetação ripária, apesar da maioria (60\%) desconhecer o conteúdo das mesmas. Mesmo entre os que declararam conhecer as leis de proteção, apenas $4(13,3 \%)$ sabiam corretamente as exigências legais para as faixas marginais em quaisquer curso de água, conforme a Lei $\mathrm{n}^{\circ}$. 12.651/2012 (BRASIL, 2012).

Todos os entrevistados afirmaram manter a vegetação ripária nativa, mesmo se a legislação permitisse sua substituição. Da mesma forma, o desmatamento foi considerado um problema por todos, sendo a substituição da paisagem nativa pelas atividades agropecuárias (ver área de estudo) a causa do aumento da temperatura, redução das chuvas e da água dos mananciais, conforme algumas citações:
"Arrendou o pasto para soja. O pior da soja é que corta a sombra. As chuvas diminuíram muito de 10 anos para cá, o sol abaixou, está mais quente" (E5).
"Tudo era Cerrado, ai desmatou para o pasto depois para a soja. Esquentou muito nos últimos 5 anos, reduziram as chuvas uns 3 anos para cá" (E7).
"O desmatamento limpou tudo. Antes da soja era criação de gado, de uns três anos para cá desmatou tudo, com a soja o clima esquentou muito, tem reduzido a chuva, este ano foi muito pouco" (E8).

\section{DISCUSSÃO}

A maioria dos entrevistados demonstrou níveis de escolaridade baixos. Resultados similares também foram constatados no município vizinho Iporá, em um estudo sobre o conhecimento popular de cigarras (SÁ et al., 2017), e outro abrangendo o conhecimento etnoornitológico de pequenos produtores rurais (SOUZA et al., 2017). O rendimento médio mensal predominante de até três salários mínimos é similar ao dos domicílios rurais da capital Goiânia (IBGE, 2010).

As espécies vegetais relatadas são predominantemente utilizadas pelos entrevistados para fins medicinais, o que também foi constatado na comunidade do entorno de um parque no município vizinho Iporá (CUNHA et al., 2007). Segundo Farnsworth et al. (1985), entre 3,5 a 4,0 bilhões de pessoas no planeta dependem de plantas para fins medicinais. Importante ressaltar que $74 \%$ das 119 drogas úteis derivadas de plantas do mundo foram descobertas a partir de informações provenientes da medicina folclórica (FARNSWORTH, 1997). Na região do Alto Rio Grande, em Minas Gerais, Rodrigues e Carvalho (2001) demonstraram aumento da importância dos raizeiros não apenas em busca de tratamento para doenças, como também para reduzir custos com remédios quimioterápicos. Um estudo etnobotânico na cidade goiana de Mossâmedes, próxima à reserva biológica da Serra Dourada, demonstrou que a maioria dos entrevistados utiliza plantas exóticas domesticadas e algum tipo de planta medicinal do Cerrado (VERDE et al., 2003). Lima et al. (2012) constataram, para uma comunidade no Cerrado mineiro, uma relação positiva entre o uso das plantas e sua disponibilidade no ambiente, evidenciando assim a importância de conservar a vegetação nativa remanescente para a população local. Assim, este estudo demonstra preliminarmente a relevância das fisionomias ripárias como fontes de fitoterápicos nas comunidades estudadas em Diorama, podendo ser este outro motivo para o estabelecimento de estratégias de conservação e manejo, apesar de que pesquisas etnobotânicas mais amplas sejam necessárias. 
A extração de madeira e a retirada de plantas para fins ornamentais representaram o segundo maior uso das espécies vegetais entre os entrevistados. Um resultado não significativo foi obtido por Cunha et al. (2007) nas cercanias de um parque municipal da cidade próxima Iporá. A lei $\mathrm{n}^{\circ}$. 12651/2012 (BRASIL, 2012) favorece o extrativismo em áreas de preservação permanente, e conforme o artigo $4^{\circ}$, §5, é permitido o uso destas áreas para a pequena propriedade ou posse rural familiar. No Brasil Central, a extração de madeira em fisionomias nativas foi uma atividade relatada por entrevistados tanto na zona rural quanto urbana. Neste contexto, Lima et al. (2012) destacam duas espécies amplamente utilizadas para obtenção de lenha e material de construção, em uma comunidade rural no norte de Minas Gerais. Ao avaliar a percepção da preservação e biodiversidade na capital Goiânia, Grande et al. (2016), encontraram significativa pressão antropogênica de remoção vegetal em fragmentos florestais urbanos, sugerindo a necessidade de inspeção e investigação. Assim, considerando todos os serviços ecossistêmicos prestados por áreas de preservação permanente (OLIVEIRA e WOLSKI, 2012), como as vegetações ripárias, torna-se necessário o monitoramento e educação ambiental destinado aos produtores rurais em Diorama, para garantir a conservação destas fisionomias no município e evitar prejuízos socioeconômicos, apesar da flexibilidade da lei.

Os entrevistados relataram 69 etnoespécies animais, uma riqueza maior em relação às 41 etnoespécies de Cunha et al. (2007), para o parque municipal na cidade vizinha Iporá. A maioria dos entrevistados declarou não utilizar as vegetações ripárias em suas propriedades para caça, o que também foi declarado pela maioria dos entrevistados de Cunha et al. (2007) em Iporá, e Grande et al. (2016) na capital Goiânia. A caça, além de ser um aspecto cultural passado entre gerações, também pode estar vinculada à carência alimentar, como encontrado no estudo de Barbosa et al. (2010), numa comunidade rural no estado da Paraíba. Com relação aos entrevistados de Diorama, provavelmente menos caça se deve à maior disponibilidade de alimentos de origem animal provindos da criação de gado, suínos e aves (ver resultados). Entretanto, a proibição das atividades de caça (BRASIL, 1967) pode ser um fator preponderante de inibição.

Contudo, a caça parece ser uma atividade significativa na área estudada, apesar de poucos entrevistados declararem exercê-la. Importante ressaltar que o tamanduá-bandeira Myrmecophaga tridactyla Linnaeus, 1758 e a anta Tapirus terrestris Linnaeus, 1758, duas espécies relatadas como caçadas, são consideradas vulneráveis (VU-vulnerable) segundo IUCN (http://www.iucnredlist.org/). Neste contexto, a caça não deve ser negligenciada na área estudada, inclusive por comprometer populações de espécies em considerável nível de ameaça. Grande et al. (2016) também alertam para a significativa pressão antropogênica de caça em fragmentos florestais urbanos na cidade de Goiânia. Os entrevistados que declararam pescar usam a atividade apenas para recreação e subsistência, o que também foi relatado nos estudos de Cunha et al. (2007) em uma localidade de Iporá, e Barbosa et al. (2017) em paisagem no norte goiano. Uma proporção significativa de entrevistados declarou ter abandonado a pesca com a redução da água e dos peixes nos mananciais. Importante ressaltar que, segundo Berkes et al. (2000), os entrevistados compreendem as causas das mudanças ambientais, pois são observadores diários das alterações provocadas.

Neste sentido, todos os entrevistados manifestaram interesse em conservar a vegetação ripária, e apesar de a maioria não explicar adequadamente (ver resultados), garantir os serviços ecossistêmicos foi o segundo maior motivo. O desmatamento foi associado ao aumento da temperatura, redução das chuvas, e diminuição da água nos mananciais do município. De fato, a remoção da cobertura vegetal natural diminui a capacidade de infiltração de água no solo, reduzindo consequentemente a recarga hídrica no lençol freático, além de aumentar riscos de erosões, rarefação da cobertura do solo e assoreamento nos mananciais (BONATO et al., 2007; FERREIRA et al., 2011). Resultados similares foram obtidos por Barreto (2007), com sojicultores de Rio Verde no sul goiano, os quais alegaram a preservação da vegetação ripária para conservar nascentes e rios, prevenir assoreamento e proteger os animais. A preocupação com a disponibilidade dos recursos hídricos foi também constatada por Américo et al. (2012), entre agricultores de Dobrada, estado de São Paulo, onde grande parte dos entrevistados relacionaram a importância da conservação das matas ciliares para preservar cursos de água e animais silvestres. Os entrevistados de Barbosa et al. (2017), em uma paisagem no norte goiano, ressaltaram a importância da mata ciliar para a manutenção de serviços ecossistêmicos, e que mudanças ambientais como desmatamento ocasionaram vários impactos ambientais e econômicos.

\section{CONCLUSÕES}

Os entrevistados em Diorama possuem ampla percepção acerca das vegetações ripárias em suas propriedades, e fazem uso significativo dos seus serviços ecossistêmicos. Da mesma forma, os 
entrevistados também demonstraram conhecimento relevante sobre a importância de sua preservação para evitar prejuízos ambientais e econômicos. Entretanto, futuramente trabalhos de conscientização ambiental deveriam ser desenvolvidos nas comunidades estudadas, considerando a extração de madeira e caça duas atividades relatadas por grande parte dos entrevistados. Mais estudos futuros sobre a percepção das vegetações ripárias pelos produtores rurais são necessários, considerando sua importância ecológica e econômica tanto no estado de Goiás, quanto no Cerrado como um todo.

\section{AGRADECIMENTOS}

A todos os produtores rurais entrevistados em Diorama, indispensáveis para o desenvolvimento deste estudo. O programa de pós-graduação em recursos naturais do Cerrado (UEG/RENAC) e o Campus UEG-Iporá forneceram importante apoio logístico. Pedro Rogério Giongo elaborou o mapa. D. A. Carvalho e D. Blamires receberam, respectivamente, as bolsas de mestrado/UEG e incentivo à pesquisa (UEG/BIP) durante parte da elaboração deste estudo. Murilo de Souza, Douglas H. Bottura Maccagnan, Lorena D'Allara Guimarães e dois revisores anônimos fizeram relevantes críticas a versões anteriores do manuscrito.

\section{REFERÊNCIAS}

AMÉRICO, J. H. P; CARVALHO, S. L.; GONZAGA, M. L.; LIMA, E. A. C. F.; ARAÚJO, C. A. M. Condiç̃̃es Ambientais de Propriedades Agrícolas e Percepção Ambiental de Produtores Rurais do Município de Dobrada - São Paulo, Brasil. Holos Environment, Rio Claro, v.2, n.2, p. 241-249, 2012.

ANDERSON, E. N. Ethnobiology: overview of a growing field. In: ANDERSON, E. N PEARSALL, D. M.; HUNN, E. S.; TURNER, N. J. (Org.). Ethnobiology. Hoboken: John Wiley\& Sons, 2011, p. 1-14.

ATLAS. Desenvolvimento Humano no Brasil: Atlas-Município-Goiás-Diorama-IDHM. Disponível em: <http://atlasbrasil.org.br/2013/pt/o_atlas/o_atlas_/>. Acesso em: 11 jun. 2016.

BARBOSA, J. A. A.; NOBREGA, V. A.; ALVES, R. R. N. Aspectos da caça e comércio ilegal da avifauna silvestre por populações tradicionais do semi-áridoparaibano.Revista de Biologia e Ciências da Terra, São Cristóvão, v. 10, n.2, p.39-49, 2010.

BARBOSA, H. O.; SOUZA, M. F.; ONDEI, L. S.; TERESA, F. B. Conhecimento ecológico local e percepção dos impactos ambientais por moradores da zona rural sobre riachos e peixes da bacia do alto Rio Tocantins, Goiás, Brasil. Ethnoscientia, Botucatu, v. 2, p. 1-20, 2017.

BARRETO, C. A. Agricultura e meio ambiente: percepções e práticas de sojicultores em Rio Verde - GO. 138f. Dissertação (Mestrado em Ciências Ambientais) - Faculdade de Saúde Pública, Universidade de São Paulo, São Paulo, 2007.

BART, D. Integrating local knowledge into experimental studies to understand the causes of environmental change. Frontiers in ecology and environment, Washington, v. 4, p. 541-546, 2006.

BERKES, F.; COLDING, J.; FOLKE, C. Rediscovery of traditional ecological knowledge as adaptive management. Ecologicalapplications, Washington, v. 10, p. 1251-1262, 2000.

BONATO, F.; MARTINS, A. K. E.; BARROS, E. K. Uso de geotecnologia para classificação de pastagens em diferentes níveis de degradação da bacia do Ribeirão Matança localizada no município de Piuim - TO. In: ANAIS XIII SIMPÓSIO BRASILEIRO DE SENSORIAMENTO REMOTO, Florianópolis: INPE, 2007, p. 791-798.

BRASIL. Lei $\mathbf{n}^{0}$ 5197, de 03 de janeiro de 1967. Dispõe sobre a proteção da fauna e dá outras providências. Diário Oficial da União - Seção 1 - 5/1/1967, Página 177. Disponível em: < http://www2.camara.leg.br/legin/fed/lei/1960-1969/lei-5197-3-janeiro-1967-364679-publicacaooriginal-1-pl.html > Acesso em 12 dez. 2018.

BRASIL. Lei $\mathbf{n}^{\circ}$ 12.651, de 25 de maio de 2012. Dispõe sobre a proteção da vegetação nativa; altera as Leis nos 6.938, de 31 de agosto de 1981, 9.393, de 19 de dezembro de 1996, e 11.428, de 22 de dezembro de 2006; revoga as Leis nos 4.771, de 15 de setembro de 1965, e 7.754, de 14 de abril de 1989, e a Medida Provisória no 2.166-67, de 24 de agosto de 2001; e dá outras providências. Diário Oficial [da] República Federativa do Brasil, Brasília, DF, 28 mai. 2012. Disponível em: < http://www.planalto.gov.br/ccivil_03/_ato2011-2014/2012/lei/112651.htm>. Acesso em: 10 mar. 2015.

BONI, V.; QUARESMA, S. J. Aprendendo a entrevistar: como fazer entrevistas em Ciências Sociais. Em tese: revista eletrônica dos pós-graduandos em sociologia política da UFSC, Florianópolis, v. 2, n. 1, janeiro-julho, p. 68-80, 2005

CLIMATE-DATA.ORG. Clima: Diorama. Disponível em: <https://pt.climate-data.org/location/312835/>. Acesso em: 01 jul. 2017.

CUNHA, H. F.; VALE, M.S.; SILVA JUNIOR, C. A. S.; CAMPOS, R. F.; CARLOS, L. O.Conhecimento empírico dos moradores da comunidade do entorno do Parque Municipal da Cachoeirinha (Iporá-Goiás). Acta ScientiarumBiologicalSciences, Maringá, v. 29, n. 2, p. 203-212, 2007.

DATASUS. Departamento de Informática do SUS: Censos 1991, 2000 e 2010 - Taxa de analfabetismo. 2016. Disponível em: 〈http://tabnet.datasus.gov.br/cgi/tabcgi.exe?ibge/censo/cnv/alfgo.def〉. Acessoem: 19 jul. 2016.

DAVIS, A.; WAGNER, J. Who knows? On the importance of identifying "experts" when researching local ecological knowledge. Human ecology: an interdisciplinary journal v. 31, p. 463-489, 2003. 
DIAMOND, J. M. Zoological classification system of a primitive people. Science, Washington, v. 151, p. 11021104, 1966.

DURIGAN, G.; SILVEIRA, E. R. D. Recomposição de mata ciliar em domínio de Cerrado. Assis, SP. Scientia Florestalis,Piracicaba n. 56, p. 135-144, 1999.

EMPERAIRE, L.; PERONI, N. Traditional management of agrobiodiversity in Brazil: a case study of manioc. Human Ecology, Switzerland v. 35, n. 6, p. 761-768, 2007.

FAHRIG, L. Effects of habitat fragmentation on biodiversity. Annual Review of Ecology, Evolution and Systematics, Palo Alto v. 38, p. 487-515.

FARIAS, G. B.; ALVES, A. G. C. Aspectos históricos e conceituais da etnoornitologia. Biotemas, Florianópolis, v. 29, n.1, p. 91-100, 2007.

FARNSWORTH, N. R.; AKERELE, O.; BINGEL, A. S.; SOEJARTO, D. D.; GUO, Z. Medicinal plants in therapy. Bulletin of the World Health Organization, Geneva,v. 63, n. 6, p. 965-981, 1985.

FARNSWORTH, N. Testando plantas para novos remédios, In: WILSON, E. O.; PETER, F. M. (Org.). Biodiversidade. Rio de Janeiro: Nova Fronteira, 1997. p. 107-125.

FERREIRA, R. A.; AGUIAR NETTO, A. O.; SANTOS, T. I. S.; SANTOS, B. L.; MATOS, E. L. Nascentes da sub-bacia hidrográfica do rio Poxim, estado de Sergipe: da degradação à restauração. Revista Árvore, Viçosa, v. 35 , n. 2, p. 265-277, 2011.

GRANDE, T.O.; P.H.P. RIBEIRO; F.R. MELO. Human perception of the conservation and biodiversity state of forest remnants under different levels of urbanization. Acta Scientiarum, Maringá, v. 38, n. 1, p. 47-58, 2016.

HINKEL, R. Vegetações ripárias: funções e ecologia. In: Anais do I Seminário de Hidrologia Florestal: Zonas Ripárias.Alfredo Wagner, Universidade Federal de Santa Catarina, 2003. p. 40-48.

HUNN, E. Ethnobiology in four fases. Journal of Ethnobiology, Tacoma, v. 27, n. 1, p. 1-10, 2007.

HUNTINGTON, H. P. Observations on the utility of the semi-directive interview for documenting traditional ecological knowledge. Arctic, Calgary, v. 51, n. 3, p. 237-242, 1998.

INSTITUTO BRASILEIRO DE GEOGRAFIA E ESTATÍSTICA: Censo demográfico. 2010. Disponível em: $<$ http://www.cidades.ibge.gov.br/xtras/perfil.php?lang=\&codmun=520710\&search=goias|diorama>. Acesso em: 01 mar. 2015.

INSTITUTO MAURO BORGES: Goiás em Dados. 2014. Disponível em: http://www.imb.go.gov.br/down/godados2014.pdf.> . Acesso em 01 jul. 2017.

INSTITUTO MAURO BORGES: Perfil Socioeconômico de Diorama. 2016. Disponível em: <http://www.imb.go.gov.br/perfilweb/perfil_bde.asp>. Acesso em: 20 jul. de 2016.

LIMA, I. L. P.; SCARIOT, A.; MEDEIROS, M. B.; SEVILHA, A. C. Divesidade e uso de plantas do Cerrado em comunidade de geraizeiros no norte do estado de Minas Gerais, Brasil. Acta BotanicaBrasilica, Belo Horizonte, v. 26, n.3, p. 675-684, 2012.

LOPES, P. F. M.; SILVANO, R.; BEGOSSI, A. Da biologia a etnobiologia - taxonomia e etnotaxonomia, ecologia e etnoecologia. In: ALVES, R. R. N.; SOUTO, W. M. S.; MOURÃO, J. S. (Org.). Etnozoologia no Brasil: importância, status atual e perspectivas futuras, Recife: NUPEEA, 2010, p. 69-94.

MEDEIROS, M. F. T.; ALVES, A. G. C.; ALMEIDA, C. F. C. B. R.; COSTA-NETO, E. M.; LINS NETO, E. M. F.; SOGLIO, F. K.; SOUTO, F. J. B.; COELHO-DE-SOUZA, G.; SOLDATI, G. T.; SILVA, H. P.; MELO, J. G.; MARQUES, J. G.; MONTEIRO, J. M.; MING, L. C.; CUNHA, L. V. F. C.; RAMOS, M. A.; HANAZAKI, N.; ALVES, R. R. N.; ALBUQUERQUE, U. P. In: ALBUQUERQUE, U. P.; ALVES, R. (Org.). Dictionary of ethnobiology and related areas. Switzerland: Springer international publishing, 2016. p. 273-310.

OLIVEIRA, T.; WOLSKI, M. S. Importância da Reserva Legal para a preservação da biodiversidade. Vivências: Revista Eletrônica de Extensão da URI, Santo Ângelo, v. 8, n. 15, p. 40-52, 2012.

PRADO, H.M.; MURIETA, R.S.S. Ethnoecology in perspective: the origins, interfaces and current trends of a growing field. Ambiente e sociedade, São Paulo, v.8, n. 4, p. 133-154, 2015.

ROCHA-MENDES, F.; MIKICH, S. B.; BIANCONI, G. V., PEDRO, W. A. Mamíferos do Município de Fênix, Paraná, Brasil: etnozoologia e conservação, Revista Brasileira de Zoologia, São Paulo, v. 22, n. 4, p. 901-1002, 2005. RODRIGUES, V. E. G.; CARVALHO, D. A. Levantamento etnobotânico de plantas medicinais no domínio do Cerrado na região do alto Rio Grande- Minas Gerais. Ciência e agrotecnologia, Lavras, v. 25, n. 1, p. 102-123, 2001.

SÁ, M. A. P.; ROMANO, C. A.; MACCAGNAN, D. H. B. Conhecimento popular de moradores do perímetro urbano de Iporá, Goiás, sobre cigarras (hemíptera: cicadidae). Gaia Scientia, João Pessoa, v. 11, n. 3, p. 243-258, 2017.

SILVA, J. F.FARIÑAS, M. R., FELFILI, J. M., KLINK, C. A. Spatial heterogeneity, land use and conservation in the Cerrado region of Brazil. JournalofBiogeography, Chicago, v. 33, p. 536-548, 2006.

SOUZA, M. F.; BARBOSA, H. O.; BLAMIRES, D. Importância cultural, ecológica e econômica de aves entre moradores de comunidades rurais do município de Iporá/Go. In: SANTOS, F. R. (Org.). Contextualizando o Cerrado Goiano: Entre questões socioeconômicas e socioespaciais e questões socioeducacionais e socioambientais. Curitiba: CRV, 2017, p. 185-202.

STEVENSON, B. M. G. Traditional knowledge and sustainable forest management. Sustanaibleforest management, Geneva,p. 18, 2015.

VERDE, G. M.; PAULA, J. R.; CANEIRO, D. M. Levantamento etnobotânico das plantas medicinais do Cerrado utilizadas pela população de Mossâmedes (GO). Revista brasileira de farmacognosia, Curitiba, v. 13, p. 64-66, 2003. 